\title{
ÖTOLDALÚ TÉRMECHANIZMUS, GYORSULÁS MEGHATÁROZÁS
}

\section{FIVE-SIDED MECHANISM, DETERMINATION OF ACCELERATION}

\author{
Popa-Müller Izolda ${ }^{1}$, Papp István ${ }^{2}$ \\ ${ }^{1}$ SAPIENTIA-Erdélyi Magyar Tudományegyetem, Müszaki és Humán Tudományok \\ Kar, Gépészmérnöki Tanszék, Románia, Marosvásárhely, Segesvári út,1/C, Fax: \\ 0265-206211,ipmuller@ms.sapientia.ro \\ ${ }^{2}$ SAPIENTIA-Erdélyi Magyar Tudományegyetem, Müszaki és Humán Tudományok \\ Kar, Gépészmérnöki Tanszék, Románia, Marosvásárhely, Segesvári út,1/C, Fax: \\ 0265-206211, pappistvan1944@yahoo.com.
}

\begin{abstract}
The aim of this thesis is the definition of the general shape of the constraint equations which are necessary to calculate the acceleration of the robot arm and the mechanisms and the presentation of their application.

After the derivation in time of the velocity (wich in general form determinate the [1] and [3]), the constraint equations of the acceleration are obtained after grouping the unknowns.
\end{abstract}

Keywords: kinematic pairs, constraints, constraints equations, acceleration.

\section{Összefoglalás}

A dolgozat célja az ötoldalú térmechanizmus gyorsulásának kiszámításához szükséges kényszeregyenletek általános alakjainak meghatározása. A kényszeregyenletek segítségével, meghatározható bármely tér vagy síkban fekvő mechanizmus tagjainak gyorsulása.

A gyorsulás kényszeregyenleteit (ami általános formában az [1] és [3] meghatároz), a sebesség kényszeregyenleteinek idő függvényében való deriválása és a kifejezések az ismeretlenek szerinti csoportosítása után kaptuk meg.

Kulcsszavak: kinematikai pár, kötöttségek, kényszeregyenlet, gyorsulás.

\section{Az ötoldalú térmechanizmus ismertetése}

Az ötoldalú mechanizmus elemei az 1. ábra szerint:

1-géptörzs;

2-fötengely;

3-hajtókar;

4-összekötőtag;

5-lengőkar.

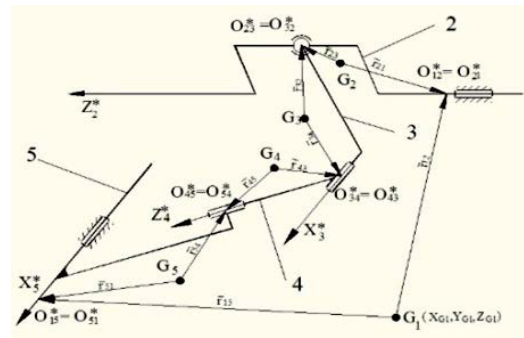

1. ábra. Ötoldalú térmechanizmus 
A program egy kívülálló rögzített rendszerhez van felírva, amelyben a géptörzs koordinátái, $X_{G i}, Y_{G i}, Z_{G i}$ értékeket kaptak. A mechanizmus bármely tagjának súlypontjához viszonyított $O_{i j}^{*}$ pontok koordinátái mindig állandók, amelyeket az $r_{i j}$ vagy $r_{i j} I$ helyzetvektorokkal határoztunk meg.

\section{A gyorsulás kényszeregyenlete- inek meghatározása}

Az ismeretlenek meghatározásához tizenhat kényszeregyenletböl alkotott rendszert írtunk fel. A mechanizmus vezetőparamétere $\psi_{2}$ szög.

A gyorsulás kényszeregyenleteinek általános alakja forgó és gömbcsuklóval kapcsolt mechanizmus esetén: A géptörzs és a fötengelyt összekapcsoló forgó csukló, gyorsulásának kényszeregyenletei:

$$
\begin{aligned}
& \ddot{X}_{G 2}-x_{21} \cdot \dot{\psi}_{2}^{2} \cdot \alpha_{12}\left(\psi_{2}, \theta_{2}, \phi_{2}\right)-y_{21} \cdot \dot{\psi}_{2}^{2} \cdot \beta_{12}\left(\psi_{2}, \theta_{2}, \phi_{2}\right)-z_{21} \cdot \dot{\psi}_{2}^{2} \cdot \gamma_{12}\left(\theta_{2}, \psi_{2}\right)=0 \\
& \ddot{Y}_{G 2}-x_{21} \cdot \dot{\psi}_{2}^{2} \cdot \alpha_{22}\left(\psi_{2}, \theta_{2}, \phi_{2}\right)-y_{21} \cdot \dot{\psi}_{2}^{2} \cdot \beta_{22}\left(\psi_{2}, \theta_{2}, \phi_{2}\right)-z_{21} \cdot \dot{\psi}_{2}^{2} \cdot \gamma_{22}\left(\theta_{2}, \psi_{2}\right)=0
\end{aligned}
$$

A fötengelyt és hajtókart összekapcsoló gömbcsukló, gyorsulás kényszeregyenletei:

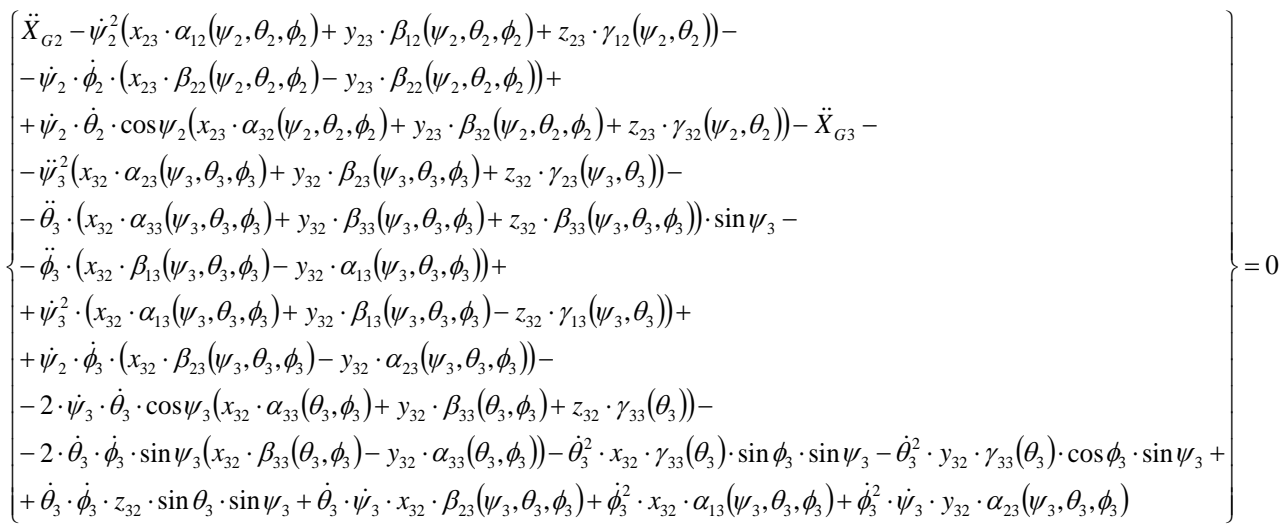




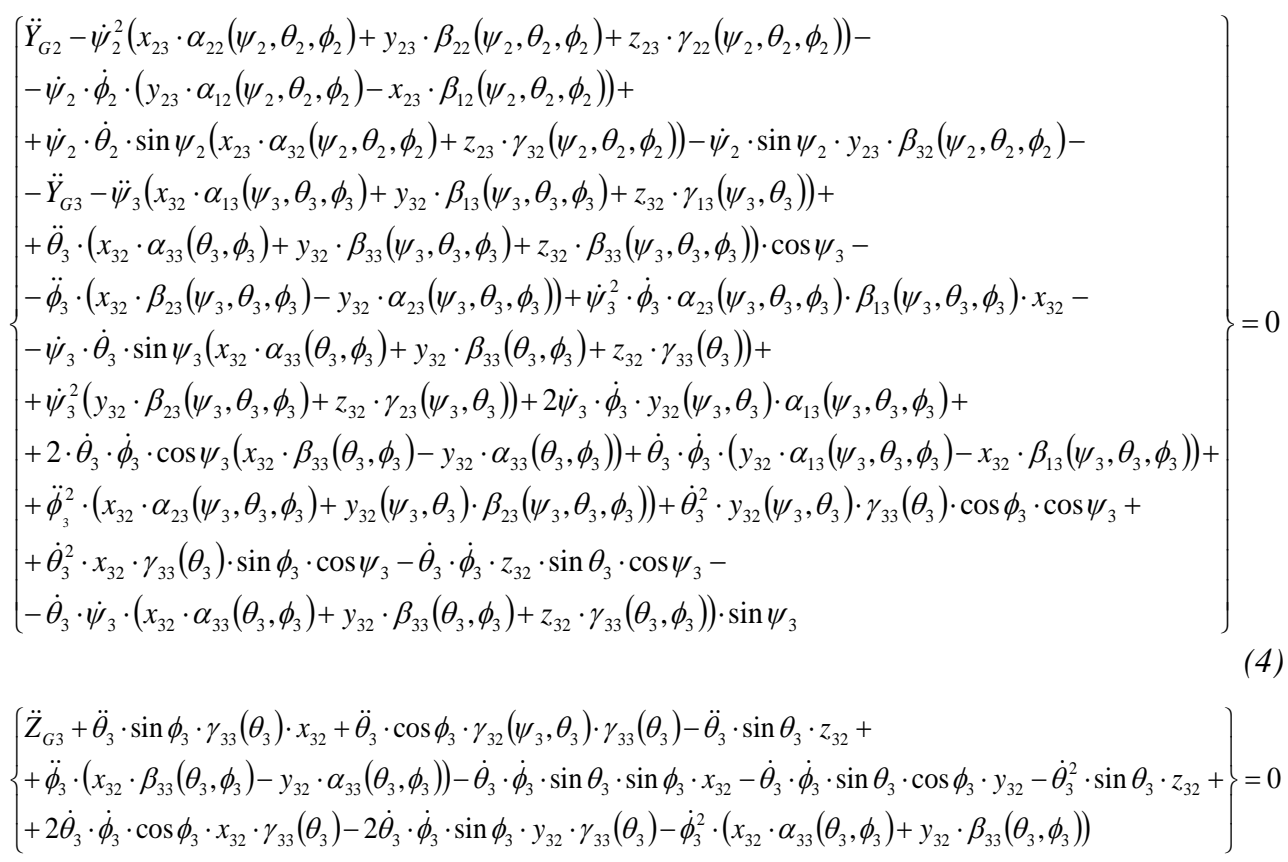

Az összekötő tag és a lengőkar között forgó csukló, gyorsulás egyenletei:

$\ddot{X}_{G 4}+\ddot{\theta}_{4} \cdot\left(x_{45} \cdot \alpha_{34}\left(\theta_{4}, \phi_{4}\right)+y_{45} \cdot \beta_{34}\left(\theta_{4}, \phi_{4}\right)+z_{45} \cdot \gamma_{34}\left(\theta_{4}\right)\right) \cdot \sin \psi_{4}+\ddot{\phi}_{4} \cdot\left(x_{45} \cdot \beta_{14}\left(\psi_{4}, \theta_{4}, \phi_{4}\right)-y_{45} \cdot \alpha_{14}\left(\psi_{4}, \theta_{4}, \phi_{4}\right)\right)+$ $+\dot{\theta}_{4} \cdot\left(x_{45} \cdot \dot{\alpha}_{34}\left(\theta_{4}\right)+y_{45} \cdot \dot{\beta}_{34}\left(\theta_{4}, \phi_{4}\right)+z_{45} \cdot \dot{\gamma}_{34}\left(\theta_{4}\right)\right) \cdot \sin \psi_{4}+\dot{\phi}_{4} \cdot\left(x_{45} \cdot \dot{\beta}_{14}\left(\psi_{4}, \theta_{4}, \phi_{4}\right)-y_{45} \cdot \dot{\alpha}_{14}\left(\psi_{4}, \theta_{4}, \phi_{4}\right)\right)-$

$-\ddot{\theta}_{5} \cdot\left(x_{54} \cdot \alpha_{35} \cdot\left(\theta_{5}, \phi_{5}\right)+y_{54} \cdot \beta_{35}\left(\theta_{5}, \phi_{5}\right)+z_{54} \cdot \gamma_{35}\left(\theta_{5}\right)\right) \cdot \sin \psi_{5}-$

$-\dot{\theta}_{5} \cdot\left(x_{54} \cdot \dot{\alpha}_{35} \cdot\left(\theta_{5}, \phi_{5}\right)+y_{54} \cdot \dot{\beta}_{35}\left(\theta_{5}, \phi_{5}\right)+z_{54} \cdot \dot{\gamma}_{35}\left(\theta_{5}\right)\right) \cdot \sin \psi_{5}=0$

$\ddot{Y}_{G 4}-\ddot{\theta}_{4} \cdot\left(x_{45} \cdot \alpha_{34}\left(\theta_{4}, \phi_{4}\right)+y_{45} \cdot \beta_{34}\left(\theta_{4}, \phi_{4}\right)+z_{45} \cdot \gamma_{34}\left(\theta_{4}\right)\right) \cdot \cos \psi_{4}+\ddot{\phi}_{4} \cdot\left(x_{45} \cdot \beta_{24}\left(\psi_{4}, \theta_{4}, \phi_{4}\right)-y_{45} \cdot \alpha_{24}\left(\psi_{4}, \theta_{4}, \phi_{4}\right)\right)+$ $-\dot{\theta}_{4} \cdot\left(x_{45} \cdot \dot{\alpha}_{34}\left(\theta_{4}\right)+y_{45} \cdot \dot{\beta}_{34}\left(\theta_{4}, \phi_{4}\right)+z_{45} \cdot \dot{\gamma}_{34}\left(\theta_{4}\right)\right) \cdot \cos \psi_{4}+\dot{\phi}_{4} \cdot\left(x_{45} \cdot \dot{\beta}_{24}\left(\psi_{4}, \theta_{4}, \phi_{4}\right)-y_{45} \cdot \dot{\alpha}_{24}\left(\psi_{4}, \theta_{4}, \phi_{4}\right)\right)-\ddot{Y}_{G 5}+$ $+\ddot{\theta}_{5} \cdot\left(x_{54} \cdot \alpha_{35} \cdot\left(\theta_{5}, \phi_{5}\right)+y_{54} \cdot \beta_{35}\left(\theta_{5}, \phi_{5}\right)+z_{54} \cdot \gamma_{35}\left(\theta_{5}\right)\right) \cdot \cos \psi_{5}+$

$+\dot{\theta}_{5} \cdot\left(x_{54} \cdot \dot{\alpha}_{35} \cdot\left(\theta_{5}, \phi_{5}\right)+y_{54} \cdot \dot{\beta}_{35}\left(\theta_{5}, \phi_{5}\right)+z_{54} \cdot \dot{\gamma}_{35}\left(\theta_{5}\right)\right) \cdot \cos \psi_{5}=0$

$\ddot{Z}_{G 4}+\ddot{\theta}_{4} \cdot\left(x_{45} \cdot \gamma_{34}\left(\theta_{4}\right) \cdot \sin \phi_{4}+y_{45} \cdot \gamma_{34}\left(\theta_{4}\right) \cdot \cos \phi_{4}-z_{45} \cdot \sin \theta_{4}\right)+$

$+\ddot{\phi}_{4} \cdot\left(x_{45} \cdot \beta_{34}\left(\theta_{4}, \phi_{4}\right)-y_{45} \cdot \alpha_{34}\left(\theta_{4}, \phi_{4}\right)\right)+$

$+\dot{\theta}_{4} \cdot\left(x_{45} \cdot \dot{\gamma}_{34}\left(\theta_{4}\right) \cdot \sin \phi_{4}+y_{45} \cdot \dot{\gamma}_{34}\left(\theta_{4}, \phi_{4}\right) \cdot \cos \phi_{4}-z_{45} \cdot \dot{\theta}_{4} \cdot \cos \theta_{4}\right)+$

$+\dot{\theta}_{4} \cdot \dot{\phi}_{4}\left(x_{45} \cdot \dot{\gamma}_{34} \cdot \cos \phi_{4}-y_{45} \cdot \dot{\gamma}_{34}\left(\theta_{4}, \phi_{4}\right) \cdot \sin \phi_{4}\right)+\dot{\phi}_{4} \cdot\left(x_{45} \cdot \dot{\beta}_{34}\left(\theta_{4}, \phi_{4}\right)-y_{45} \cdot \dot{\alpha}_{34}\left(\theta_{4}, \phi_{4}\right)\right)-\ddot{Z}_{G 5}-$

$-\ddot{\theta}_{5} \cdot\left(x_{54} \cdot \gamma_{35} \cdot\left(\theta_{5}\right) \cdot \sin \phi_{5}+y_{54} \cdot \gamma_{35}\left(\theta_{5}\right) \cdot \cos \phi_{5}-z_{54} \cdot \sin \theta_{5}\right)-$

$\left.-\dot{\theta}_{5} \cdot\left(x_{54} \cdot \dot{\gamma}_{35} \cdot\left(\theta_{5}\right) \cdot \sin \phi_{5}+y_{54} \cdot \dot{\gamma}_{35}\left(\theta_{5}\right) \cdot \sin \phi_{5}\right)-z_{54} \cdot \dot{\theta}_{5} \cos \theta_{5}\right)=0$ 
$\ddot{\theta}_{4} \cdot\left(\gamma_{34} \cdot \gamma_{14}^{0} \cdot \sin \phi_{4}+\gamma_{34} \cdot \gamma_{24}^{0} \cdot \cos \phi_{4}+\gamma_{34} \cdot \sin \theta_{4}\right)+\dot{\theta}_{4} \cdot\left(\dot{\gamma}_{34} \cdot \gamma_{14}^{0} \cdot \cos \phi_{4}-\dot{\gamma}_{34} \cdot \gamma_{24}^{0} \cdot \sin \phi_{4}+\dot{\gamma}_{34} \cdot \sin \theta_{4}\right)+$

$+\ddot{\phi}_{4} \cdot\left(\beta_{34} \cdot \gamma_{14}^{0}-\alpha_{34} \cdot \gamma_{24}^{0}\right)+\dot{\phi}_{4} \cdot\left(\dot{\beta}_{34} \cdot \gamma_{14}^{0}-\dot{\alpha}_{34} \cdot \gamma_{24}^{0}\right)-\ddot{\phi}_{5} \cdot\left(\beta_{35} \cdot \gamma_{15}^{0}-\alpha_{35} \cdot \gamma_{25}^{0}\right)-\dot{\phi}_{5} \cdot\left(\dot{\beta}_{35} \cdot \gamma_{15}^{0}-\dot{\alpha}_{35} \cdot \gamma_{25}^{0}\right)-$

$-\ddot{\theta}_{5} \cdot\left(\gamma_{35} \cdot \gamma_{15}^{0} \cdot \sin \phi_{5}+\gamma_{35} \cdot \gamma_{25}^{0} \cdot \cos \phi_{5}+\gamma_{35} \cdot \sin \theta_{5}\right)-\dot{\theta}_{5} \cdot\left(\dot{\gamma}_{35} \cdot \gamma_{15}^{0} \cdot \cos \phi_{5}-\dot{\gamma}_{35} \cdot \gamma_{25}^{0} \cdot \sin \phi_{5}+\dot{\gamma}_{35} \cdot \sin \theta_{5}\right)=0$

A hajtókar és összekötőtag közötti forgó csukló, öt gyorsulás egyenletét hasonlóan írtuk fel, az összekötö tag és lengökar egyenletéhez képest, csak a kollinearítás feltétele az X tengelynek felel meg.

A lengőkar a géptörzshöz kapcsoló forgó csukló gyorsulás egyenletei:

$\ddot{Y}_{G 5}-\ddot{\theta}_{5} \cdot\left(x_{51} \cdot \alpha_{35}+y_{51} \cdot \beta_{35}+z_{51} \cdot \gamma_{35}\right) \cdot \cos \psi_{5}-\dot{\theta}_{5} \cdot\left(x_{51} \cdot \dot{\alpha}_{35}+y_{51} \cdot \dot{\beta}_{35}+z_{51} \cdot \dot{\gamma}_{35}\right) \cdot \cos \psi_{5}=0$

$\ddot{Z}_{G 5}+\ddot{\theta}_{5} \cdot\left(x_{51} \cdot \gamma_{35}\left(\theta_{5}\right) \cdot \sin \phi_{5}+y_{51} \cdot \gamma_{35}\left(\theta_{5}\right) \cdot \cos \phi_{5}-z_{51} \cdot \sin \theta_{5}\right)-\dot{\theta}_{5}^{2} \cdot \sin \theta_{5} \cdot \sin \phi_{5} \cdot x_{51}-$

$-\dot{\theta}_{5}^{2} \cdot \sin \theta_{5} \cdot \cos \phi_{5} \cdot y_{51}-\dot{\theta}_{5}^{2} \cdot \cos \theta_{5} \cdot z_{51}=0$

A mechanizmus ismeretlen paraméterei az oszlopmátrix értékei:

$\left[Q_{i}\right]^{T}=\left(\ddot{X}_{G 2}, \ddot{Y}_{G 2}, \ddot{X}_{G 3}, \ddot{Y}_{G 3}, \ddot{Z}_{G 3}, \ddot{X}_{G 4}, \ddot{Y}_{G 4}, \ddot{Z}_{G 4}, \ddot{Y}_{G 5}, \ddot{Z}_{G 5}, \ddot{\psi}_{3}, \ddot{\theta}_{3}, \ddot{\phi}_{3}, \ddot{\theta}_{4}, \ddot{\phi}_{4}, \ddot{\theta}_{5}\right)$

A fenti egyenletekből az ismeretlenek csoportosításával kifejezhetők az „A” és a „B” mátrix tagjai.

A deriválásokat a [2].170 old.5.179, 164 old,5.172 általánosan megfogalmazott képletek sajátos alakra hozása szerint írtuk fel.

\section{Következtetések}

A kényszeregyenletek segítségével bármely tér vagy síkban fekvő mechanizmus tagjainak gyorsulása meghatározható különösebb mozgásegyenletekre jellemző számítások nélkül.

Ennek a módszernek a használatával, lehet a legpontosabban meghatározni a térmechanizmusok tagjaihoz tartozó központi tehetetlenségi fötengelyek gyorsulásait, a saját és a külső rögzített koordináta rendszerhez viszonyítva.
A tudományos eredményeket hasznosítani lehet, bármely karos mechanizmus és robotok gyorsulásainak kiszámításánál,valamint alkalmazási lehetőséget nyújt új és hatékony laborgyakorlatok kialakításánál.

\section{Szakirodalmi hivatkozások}

[1] Papp, I.,: Contribuţii la echilibrarea dinamică a mecanismelor spaţiale. Teză de doctorat, Cluj Napoca, 2000

[2] Papp, I.,: Mechanizmusok elmélete, Scientia Kiadó, Kolozsvár, ISBN 978-973-1970-29-5, 2010

[3] Papp, I., Popa-Müller, I.,: Karos mechanizmus kinematikai elemzése kényszeregyenletekkel, 1298 számú Kutatási szerződés a Sapientia Alapítvány Kutatási Programok Intézetével, 2005. 